\title{
LA FEMINIDAD DISNEY: EL DESARROLLO SOCIAL DE LA MUJER Y SUS CONSECUENCIAS EN LA REGULACIÓN CONSTITUCIONAL
}

\author{
THE DISNEY FEMININITY: THE SOCIAL DEVELOPMENT OF WOMEN \\ AND ITS CONSEQUENCES ON CONSTITUTIONAL REGULATION
}

\author{
María Francisca Zaragoza-Martí \\ Universidad de Alicante, Alicante / España \\ maria.zaragoza@ua.es \\ https://orcid.org/0000-0003-3912-0395
}

Recibido/Received: 28/04/2020

Modificado/Modified: 12/06/2020

Aceptado/Accepted: 15/06/2020

\section{RESUMEN}

La posición de la mujer es observada y analizada desde todas las esferas de la sociedad, lastrada durante muchos lustros por la división patriarcal de la sociedad. Una posición a la sombra de los hombres, comúnmente aceptada por nuestra tradición y costumbres, pues ya desde la infancia se nos inculca una peculiar visión del mundo, idealizado en las películas infantiles, donde se distribuyen roles y estereotipos divergentes entre géneros. Disney ha mermado durante muchas décadas el desarrollo de la personalidad femenina y la posición de la mujer en la sociedad, a través de las protagonistas femeninas en sus películas. Si bien el rol y las capacidades de las mismas han sufrido un empoderamiento acorde con la evolución de la sociedad, aún hoy siguen transmitiendo roles y estereotipos que difuminan negativamente la figura de la mujer en la organización jurídico-política y social contemporánea, como se observa en nuestra norma marco, la Constitución Española.

\section{PALABRAS CLAVE}

Estereotipo; mujer; Disney; igualdad constitucional; sociedad patriarcal.

\section{SUMARIO}

1. Introducción. 2. La influencia de los estereotipos Disney en la configuración social de género. 3. Rompiendo los estereotipos: en busca de la igualdad de género desde la perspectiva constitucional. 4. A modo de conclusión. Bibliografía.

\footnotetext{
ABSTRACT

The position of women is observed and analyzed from all spheres of society, weighed down for many decades by the patriarchal division of society. A position in the shadow of men, commonly accepted by our tradition and customs, since from childhood a peculiar vision of the world is instilled in us, idealized in children's films, where divergent roles and stereotypes are distributed between genres. Disney has for many decades undermined the development of the female personality and the position of women in society through the female leads in its films. Although their role and capacities have been empowered in accordance with the evolution of society, even today they continue to transmit roles and
} 
stereotypes that negatively blur the figure of women in contemporary legal-political and social organization, as observed in our framework standard, the Spanish Constitution.

\section{KEYWORDS}

Stereotypes; Woman; Disney; Constitutional equality; Patriarchal society.

\section{CONTENTS}

1. Introduction. 2. The influence of Disney stereotypes on the social configuration of gender. 3 . Breaking stereotypes: in search of gender equality from the constitutional perspective. 4. By way of conclusion. References.

\section{INTRODUCCIÓN}

El ser humano es un ser eminentemente social, acostumbrado a vivir en entornos donde las relaciones sociales fomentan el desarrollo de la personalidad, determinan las pautas del comportamiento personal y sin duda, también, configuran la división de la sociedad en roles y estereotipos fraguados por la costumbre, los mitos, la historia y los medios de comunicación. De esta forma, hombres y mujeres, niños y niñas se ven inmersos en la representación de papeles homogéneos, en su origen, pero muy heterogéneos en su significado y resultado, puesto que no son distribuidos según capacidades y habilidades, sino en atención a criterios de género.

Un canal promotor de esta radical distinción son sin duda los medios de comunicación, con carácter general y la cinematografía, con carácter particular. Son numerosas las investigaciones (Dorfman y Mattelart, 1972; Thompson y Zerbinos, 1995; Giroux, 2001; González, Villasuso y Rivera, 2012; Marín Díaz y Solís, 2017; Osuna-Acedo, Gil-Quintana y Cantillo Valero, 2018) que atestiguan que los medios de comunicación y sus manifestaciones de divertimento influyen en las personas (Aguado Peláez y Martínez García, 2015), pero no sólo de forma temporal, puntual o momentánea, sino también de forma más permanente y durante las etapas más significativas del desarrollo cognitivo y personal. En concreto, como afirma Pereira (2006), la información que nos llega a través de la cinematografía es capaz de provocar cambios, emociones y alcanzar a toda la población de una manera transparente, dado que, según Matarón (2015) las películas, además de potenciar la fantasía y la creatividad, son también un mecanismo trasmisor de opiniones, juicios, estereotipos, prejuicios y valores que, en mayor o menor medida, van a ir marcando el camino de las acciones que los infantes van a realizar en la etapa más importante de su desarrollo. En consecuencia, la sociedad es reflejo del aprendizaje constante al que la ciudadanía se encuentra sometida, resultado de conjugar las vivencias adquiridas con los anhelos y las aspiraciones ideales que el entorno comunicativo nos muestra como reales.

La cinematografía (junto con otros agentes socializadores, como la familia o la escuela, tradicionalmente), dota a los individuos de determinados valores y herramientas con las que dar forma al comportamiento humano; es decir, ayudan a construir identidades y a establecer los sistemas simbólicos a través de los que los discursos y el imaginario se trasmiten (Belmonte y Guillamón, 2008). En especial, el cine infantil o de animación dirigido a sujetos moldeables e influenciables, justamente en las etapas de desarrollo madurativo más importantes en la construcción del conjunto de valores y principios que rigen la vida de las personas y, por ende, de la sociedad en la que conviven. Como acertadamente apuntan Marín Díaz y Solís (2017), el cine de animación está sustentado en contenidos de corte 
económico, de género, raciales... que lo convierte en la clave en la generación de opiniones y actitudes y en la construcción de estereotipos, valores y contravalores. Es ahí, por tanto, donde debemos analizar la correcta correlación entre la transmisión de valores e ideales y su plasmación en conductas aceptables socialmente.

Ninguna duda cabe que el emporio de la ilusión infantil se encuentra en manos de grandes factorías cinematográficas como Disney, quien a través de sus películas infantiles (y en ocasiones también las de adultos) se acomoda en las vidas de millones de personas, generando mundos de ilusión, fascinantes combinaciones de acciones heroicas con deseos inalcanzables, los cuales se entrelazan en la personalidad de los y las infantes y adolescentes inconscientemente, conformando un conjunto de valores, principios y creencias no del todo adecuadas para una sociedad como la actual. La sociedad global contemporánea impone la necesidad de una 'multiconvivencia' diversa entre iguales, con unos valores democráticos y sociales de derecho comunes, a través de los que se garantice el adecuado desarrollo de las sociedades y de los individuos que las conforman, salvaguardando una adecuada convivencia multiétnica, multirracial o multicultural, sin necesidad de recurrir a diferencias estamentales clásicas.

Desafortunadamente, la influencia de los mass media (el discurso de los diez grandes imperios de la comunicación presenta, según Carmona (2007), propaganda política que influye a favor de la ideología conservadora de la ciudadanía, modelando sus mentes y lavando sus cerebros) trasgrede esta armonía pretendida para arrojar a la sociedad individuos influenciados por un orden social injusto, como menciona Digón (2006), naturalizando las jerarquías de raza, clase, cultura y género. Reflejo de ello, como veremos en la primera parte de este artículo, es la posición desigualitaria en la que se encuentra la mujer dentro del orden social, laboral, académico y personal actual, consecuencia directa de siglos de perpetuación clásica del hombre sobre la mujer, posiciones divergentes y subordinadas entre el género masculino y el género femenino, entre el poder y la autoridad de los niños y la dulzura y la sumisión de las niñas, promovido por las películas Disney.

Incluso en nuestra Carta Magna, ya desde sus orígenes, se puede observar la dicotomía entre los géneros, con una ausencia absoluta de lo que la Plataforma de Organizaciones Feministas de Madrid vino a denominar, durante el proceso constituyente de 1978, "paridad democrática" (actualmente democracia paritaria), es decir, inexistencia constitucional del poder constituyente femenino. En atención a ello, Torres Díaz (2018) sostiene que el texto constitucional no recoge las aspiraciones de las mujeres como sujetos constituyentes, sino que, como nos indica Gómez Fernández (2017), el consenso constitucional dejó a un lado a la mitad del ser social sobre el que debe actuar el texto fundador. Ahora bien, ¿ello quiere decir que nuestra constitución es inconstitucional en base a su propio principio de igualdad? $\mathrm{O}$, simplemente, ¿es el resultado histórico de un momento determinado, bajo circunstancias concretas, cuya promulgación supuso y sigue suponiendo, un avance paulatino hacia la modernidad democrática? Una controversia fuertemente debatida entre la doctrina y que, como todo asunto jurídico-político, encuentra diversas interpretaciones, como podremos comprobar en la segunda parte de este trabajo.

\section{LA INFLUENCIA DE LOS ESTEREOTIPOS DISNEY EN LA CONFIGURACIÓN SOCIAL DE GÉNERO}

La filmografía infantil de la factoría Disney se ha encargado de educar en valores conservadores en el respeto a la autoridad, la jerarquía social, el papel central de la familia 
nuclear tradicional, el mantenimiento de la ideología patriarcal, el refuerzo de las diferencias raciales y la desigualdad de clase, la defensa del consumismo, el patriotismo o la democracia entendida como libertad individual para elegir entre diversos productos de consumo (López y De Miguel, 2013). Lo cual no es nocivo en sí mismo, puesto que los individuos necesitamos erigirnos sobre un conjunto de principios y valores que den sentido a nuestra existencia, pero no es correcto cuando ello se hace menoscabando el desarrollo de una parte de la población a favor de la otra.

Entre los rasgos simplificados en el lenguaje audiovisual encontramos el género (Castro, 2008), marcado a su vez por el estereotipo de la mujer, dado que ello supone la generalización de determinadas atribuciones en base a la pertenencia a un determinado grupo, dividiendo aspectos vitales en femeninos y en masculinos, creando modelos de conducta divergentes según sea un hombre o una mujer, de forma que, como indican Loscertales Abril y Núñez Domínguez (2009), acaban siendo asimilados y autoatribuidos por los grupos que se estereotipan. $\mathrm{Y}$ es que una mujer no nace siendo amable, formal o educada (Stolke, 2004), como así lo muestra, por ejemplo, Disney, sino que es la propia sociedad la que moldea dichos caracteres en la figura de la mujer, justamente a través de esas creencias y estereotipos que la sociedad tradicionalmente transmite como adecuados, consecuencia de la impregnación audiovisual constante desde la niñez.

De hecho, si partimos de la hipótesis de Hyde (2005), la mayoría de las características psicológicas son compartidas por los géneros, siendo mayor la variabilidad entre individuos que entre género, lo cual desafía la concepción del sentido común 'estereotípica' de que existen grandes diferencias intergrupales, que permitirían caracterizar a quienes pertenecen a uno u otro grupo. La creencia en lo contrario es el mecanismo de bloqueo para que fluya una adecuada relación entre los individuos con independencia de su género, debiendo aparcar las imágenes sociales trasmitidas por los estereotipos cinematográficos, replicados en la estratificación social, ya que, según Aguado Peláez y Martínez García (2015), la construcción de intereses y preferencias entorno al género, interiorizadas desde la infancia, se encuentran impregnadas por patrones de desigualdad social y cultural.

De igual forma lo afirman Martínez y Merlino (2006), ya que la realidad creada por los medios propone patrones de conducta y de actitudes que pueden irse incorporando desde muy temprana edad en los esquemas cognitivos y emocionales de los receptores, debido a que, desde los primeros años, están expuestos a una gran cantidad de material cultural y mediático, que trasmiten representaciones sociales que pueden crear esquemas de pensamiento y comportamiento en los niños y las niñas. Es más, los medios de comunicación no se limitan sólo a retrasmitir 'el partido de la vida', a reflejar la realidad, sino que en buena medida crean y moldean la misma, a través de modelos, patrones, valores, actitudes y aptitudes de sus protagonistas, que de forma repetitiva se incrustan en la memoria colectiva de la sociedad.

Ese es el efecto que provoca la filmografía Disney a través de los personajes de príncipes y princesas, con vestidos y armaduras impecables, sedosos pelos, innumerables dones (mágicos o no), espectaculares casas y finales siempre felices, donde el bien vence al mal. Reproducen cuentos populares, costumbres ancestrales, comunidades tradicionales donde cada cual sabe qué sitio debe ocupar, con independencia de su voluntad o sus capacidades. $\mathrm{Y}$, en consecuencia, diseñan la interpretación del mundo desde dos realidades diferentes y bien diferenciadas: por un lado, la masculinidad, vinculada a la violencia, al dominio, al riesgo, a la habilidad y a la inteligencia, ya que es el héroe (y no la heroína) quien encarna valores positivos y restablece el orden y, por otro lado, la feminidad, unida a la debilidad, a la imprudencia, a la bondad, a la pasividad y a los valores estéticos (Porto Pedrosa, 2010). 
Las películas infantiles siguen un patrón de reproducción similar que, con independencia de la trama o historia que relatan, reflejan todos o alguno de los valores clásicos enumerados por Porto Pedrosa (2010): amistad, amor, belleza interior, bondad, comprensión, compromiso, fidelidad, humildad, igualdad, respeto, responsabilidad, solidaridad, superación personal, tolerancia, valentía y verdad. Por el contrario, los antivalores (arrogancia, egoísmo, envidia, hipocresía...) no se muestran con tanta claridad a lo largo del film, sino sólo en momentos puntuales en los que se quiere hacer sucumbir a la protagonista femenina, en ese afán por resaltar la fragilidad de la mujer, la cual no puede sino tener que ser salvada por su príncipe azul. Si estuviésemos en una clase de gramática lingüística, podríamos afirmar que en una película infantil Disney, los hombres son el sujeto principal de la oración y las mujeres sólo uno de los objetos de la misma, sin relevancia dentro de la oración, ya que sin ella posiblemente la frase contendría el mismo significado.

Si observamos dicha filmografía podemos encontrar elementos coincidentes en todos los largometrajes, en mayor o menor medida, encarnados por los personajes femeninos y masculinos, encontrándose la mujer en el denominado primer cuadrilátero de la feminidad (Aguado Peláez y Martínez García, 2015): un marco metafórico que describe el ideal de mujer ligado a la belleza, a la dulzura, a la bondad (esencialista) y a la alegría conformista (sumisa). De esta forma, nos dice Puelo (2000), incitan y convencen, amablemente, a través de múltiples mecanismos de seducción a las mismas mujeres para que deseen llegar a ser como esos modelos femeninos estereotipados. Disney actúa como anestesia sociocultural, promoviendo la perpetuación de estereotipos, roles, creencias y culturas no acordes con una sociedad moderna y avanzada, donde las mujeres y los hombres pueden desarrollar idénticas actividades con capacidades y habilidades coincidentes, en consonancia con la sociedad actual. No es posible seguir manteniendo una distribución de roles basada en una clasificación doméstica/sexual donde la mujer sólo es un reflejo del hombre, situada en un segundo plano o, como lo llama Torres Díaz (2019), sujeta a una subjetividad periférica. El zapato de cristal por una vida de ensueño se nos ha convertido en un techo de cristal infranqueable para las mujeres, como consecuencia de ese pensamiento patriarcal arraigado en la conciencia social de una humanidad creada y dominada por hombres.

Cierto es que la sociedad avanza, se desarrolla, crece, cambia y se adapta a las nuevas necesidades, a las exigencias de un conjunto cada vez más empoderado, que reclama igual visibilidad, relevancia, respeto y valor que el hombre, exigiendo ser sujeto de derechos de forma real y efectiva y no sólo meras aspiraciones tecnócratas de la maquinaria democrática masculina. Este cambio tiene reflejo también en la filmografía Disney, pues las actuales protagonistas femeninas ya no necesitan ser siempre salvadas por un hombre (como en Brave o Frozen en contraposición a Cenicienta o Ariel) y reflejan valores vitales contemporáneos, donde su voluntad es considerada, donde pueden ser independientes, valerosas, inteligentes y capaces de hacer frente a todo un reino. Esta nueva generación de princesas, como indican González, Villasuso y Rivera (2012), busca promover un ambiente de justicia, igualdad, reconocimiento $\mathrm{y}$, sobre todo, dar a entender que son completamente capaces de defenderse ellas mismas. Pero, aun así, a pesar de desplazar parte de los valores tradicionales de corte masculino, resaltando aquellos otros más contemporáneos (mayor libertad, autoestima e independencia), lo cierto es que los personajes femeninos siguen unidos a personajes masculinos de mayor relevancia y siguen vinculadas al cuidado y al sacrificio de los que de ellas dependen (por ejemplo, en Frozen II-estrenada en noviembre de 2019- Elsa debe dejar de ser reina para convertirse en el quinto elemento, la unión insoslayable que mantiene unido al mundo, cuidando de su bienestar; es decir, de nuevo, se resalta el carácter de cuidadora y benefactora del personaje femenino, en perjuicio del 
ejercicio del más alto cargo de Arendelle, el de Reina).

Por tanto, la divergencia de género, la diferencia entre hombres y mujeres, sigue estando presente en la filmografía Disney, a pesar de la redefinición de las características propias del rol masculino y el rol femenino, como consecuencia del crecimiento, evolución y desarrollo de la propia sociedad. Se sigue mostrando una configuración androcentrista de la sociedad, atribuyendo funciones a hombres y a mujeres, con exigencias y responsabilidades diferentes, atributos propios del hombre y de la mujer que prefiguran la confección social desde un prisma desigualitario. Y ello llega a todos los hogares de forma inconsciente y repetitiva a lo largo de las diferentes etapas de desarrollo de la personalidad, de forma que se promueven unas actitudes sociales ya marcadas por unos cánones inadecuados, frente a los que la sociedad permanece inmóvil, justamente porque, como indican Osuna-Acedo, Gil-Quintana y Cantillo Valero (2018), la estética de las imágenes utilizadas emplea técnicas de seducción que impactan en nuestras emociones. Desafortunadamente, las llevamos ya impregnadas en el ADN, imbuidas en nuestra cultura, como parámetros de interpretación, cabe decir, inadecuados, que nos hacen aceptar una sociedad definida o clasificada en roles y estereotipos que no responden a las capacidades y habilidades de mujeres y hombres.

Y esta 'tradicional configuración social' impregnó, también, el proceso de transición democrática de la sociedad española, al concebir la norma suprema del ordenamiento jurídico español, la Constitución Española, viciada en su origen, en cuanto que el principio de no discriminación ante la ley por razón de sexo (artículo 14 de la Constitución Española) se quebraba desde los primeros artículos de la Carta Marga de forma explícita, pero también implícitamente a lo largo de todo el texto. Quizás, porque no en vano, nos recuerda Sevilla Merino (2006), la Constitución Española tuvo 'padres fundadores' (siendo éstos sólo 7) y no 'madres fundadoras' (que sí, las hubo, pero las 27 mujeres parlamentarias cuyas hazañas sólo quedaron recogidas en los debates parlamentarios del proceso constituyente, cayeron en el olvido), como a continuación exponemos.

\section{ROMPIENDO LOS ESTEREOTIPOS: BUSCANDO LA IGUALDAD DE GÉNERO DESDE LA PERSPECTIVA CONSTITUCIONAL}

El mundo global con el que convivimos pone de manifiesto la estrecha interrelación entre los diferentes parámetros o elementos de configuración del mismo (Zaragoza-Martí, 2017), poniendo en el punto de mira la evaluación de aquellas directrices del pasado que no concuerdan con la nueva visión social. Especialmente, aquellas centradas en la salvaguarda de los derechos, deberes y libertades de los individuos en plena igualdad, ya que es importante señalar (Instituto Andaluz de la Mujer, 2015) que la igualdad es lo contrario de desigual, no la diferencia, superando los estereotipos o ideas preconcebidas sobre las características que deben tener los hombres y las mujeres.

Somos el resultado de la evolución, del conjunto de experiencias, valores, ideas, y principios que a lo largo de la historia se han ido acaeciendo, auspiciadas y fomentadas por determinados agentes socializadores, desde el prisma y la historiografía eminentemente masculina. Como nos indica Stuven (2013), a nivel intelectual, tanto desde la historia, la sociología como la psicología, recién en las últimas décadas del s. XX se pudo trascender la separación rígida entre un espacio femenino y otro masculino, el primero radicado en el hogar y el segundo en el espacio público, como manera de visualizar la realidad social interactiva y el rol de cada sexo en ella. Pero los roles, en sí mismos, también son apreciaciones culturales, enseñanzas sociales adquiridas que, como tales, se pueden cambiar, 
ya que, como nos indica Graciela Cayuso (2009), la vigencia de los derechos, entendidos como porciones de libertad, requieren de la posibilidad de optar y optar supone elegir y elegir reconoce a la libertad como presupuesto ineludible dentro de un sistema democrático constitucional conducente al principio de igualdad. Actúa pues, la igualdad, como nexo mínimo transversal que garantiza la dignidad de la persona en el disfrute de los derechos que le son propios, como basamento del ordenamiento jurídico contemporáneo.

Ahí reside la importancia del cambio en la figura de la mujer, en la necesidad de aunar esfuerzos, no sólo del sector femenino, sino también de los hombres, de las instituciones, de la función pública $\mathrm{y}$, cómo no, de la legislación para conseguir una plena y efectiva igualdad, sin necesidad de seguir inmersos en los bucles idílicos que preconiza Disney.

Para ello, la igualdad de mujeres y hombres en poder y derechos, en autoridad y reconocimiento, supone un cambio estructural que ha de reflejarse en la Constitución (Esquembre Cerdá, 2016), como marco de referencia dentro del que se ha de conjugar la convivencia normativa con los aspectos sociales, culturales, económicos y personales de la mujer, porque mientras encontramos miles de reclamos en el ámbito público, en el privado se desvanecen. En este aspecto opina de igual manera Renau i Manén (2005) cuando afirma que mientras se proclama la ciudadanía de las mujeres en lo público, siguen siendo con frecuencia súbditas en lo privado, pues se han convertido, según Martínez Sampere (2014), en el estado de bienestar del resto de la población, sin el reconocimiento adecuado por ello, sin, podríamos decir, la consiguiente igualdad constitucional que les sirva de baluarte.

Si examinamos la Constitución Española nos encontramos con términos, acepciones y configuraciones normativas que suscitan debate dentro de la comunidad académica. En ella, encauzar la igualad es un dilema jurídico dentro de un sistema constitucional complejo, resultado de una historia convulsa escrita en clave masculina y heredera de una transición marcada por la permanencia normativa. Esta exclusión femenina, nos recuerda Aba Catoria (2014), ha encontrado en el Derecho su aliado perfecto como sistema de legitimación del patriarcado, sirviéndose de la construcción de las categorías jurídicas, los principios y las instituciones que excluyeron a las mujeres del reconocimiento como sujeto político-jurídico y las dejó desprovistas de toda capacidad y sin ningún papel activo en la vida pública.

En la historia del constitucionalismo español, efectivamente, la mujer quedó excluida del ámbito social, político, económico y jurídico, subordina al hombre por la justificación de su incapacidad natural. Los argumentos que suelen darse para corroborar dichas tesis son básicamente dos, nos recuerda Álvarez Rodríguez (2020): la escasísima participación femenina en el ámbito parlamentario, consecuencia de su inexistencia pública y la irrelevancia de la igualdad de género en el ámbito político-constitucional. Sin embargo, si nos sumergimos en la realidad histórica del constitucionalismo español previo a 1978, a través de los incipientes movimiento feministas, encontraremos que sí hubo mujeres, pocas, que dejaron su impronta en el ámbito público o semipúblico, mediante su participación en el reconocimiento del ejercicio de los derechos de las mujeres, como estandartes del constitucionalismo moderno (Clara Campoamor, Margarita Nelken y Victoria Kent en los debates parlamentarios de 1931 o la actuación, no exenta de críticas, de Belén Landáburu, como única mujer ponente en la Ley de Reforma Política de 1977, entre otras).

A pesar de ello, en 1978, se volvió a acallar las voces femeninas en el proceso constituyente, puesto que el mismo sólo se recuerda en lenguaje masculino, pero del que mucho tuvieron que decir las 27 parlamentarias que, tras siglos de exclusión, pudieron iluminar la oscuridad en la que estaba sumida la mujer como sujeto de derechos constitucionales. Estas mujeres actuaron como bisagra de cambio y transición hacia una democracia participativa e inclusiva, aunque bien nos recuerda Martín Sánchez (2014) que 
la comprensión del texto constitucional sólo puede hacerse desde el conocimiento de su contexto histórico. De ahí que la Constitución de 1978 fuera lo que es, un texto normativo garantista a nivel general, creado mediante el consenso político, fruto del constitucionalismo democrático y heredera de su tiempo, pero también una oportunidad perdida para situar a la mujer en pie de igualdad con el hombre, superando la 'otredad constitucional' (Torres Díaz, 2019) en la que históricamente se encuentra el género femenino, ya que, de nuevo, la mujer quedó fuera del pacto constituyente.

Para Gómez Fernández (2019), la Constitución Española nos ha traído hasta donde estamos y no ha quedado obsoleta, pero, sin embargo, este cuerpo jurídico está desconectado de la realidad jurídico-social, es decir, ha dejado de tener relación, comunicación o enlace con la parte de la sociedad cuyas opciones políticas fundamentales, teóricamente, congrega. Es más, en base a datos estadísticos (datos del INE de 2018 establecen que el 50,9\% de la población española son mujeres; a enero de 2020 hay 934.731 mujeres más que hombres en España), esta autora afirma que no es razonable que siga existiendo una discriminación transversal, extendida y omnipresente, por razón de género en la organización de la sociedad mundial y de nuestra propia sociedad, considerada a nivel nacional, regional o local.

Pero la numerología estadística no es suficiente, no debemos formar parte de la sociedad simplemente porque seamos superiores en número, sino porque una sociedad democráticamente avanzada no se puede sustentar sobre una división de género: esto no es una liguilla entre amigos a la que se nos invita (a las mujeres) para jugar un partido y demostrar así que son (los hombres) capaces de considerar las necesidades de la otra mitad, aunque sea para algo concreto y puntual. Esa no es la democracia paritaria que exige el iusfeminismo, ya que no es, como recuerda Gómez Fernández (2019), una propuesta basada en una división del mundo en dos mitades, sino que deviene, según Martínez Sempere (2005), una exigencia democrática desde el momento en que lleva implícito un reconocimiento de la mixitud de la humanidad y, por ende, una reflexión inaplazable sobre la necesidad de un nuevo contrato social de mujeres y hombres.

Cierto es que la propia Constitución Española recoge y promueve la igualdad (tanto material como formal) como principio político, pero dicha igualdad, nos comenta Soler Sánchez (2012), es de partida un valor que se manifiesta a lo largo del texto constitucional en principios, normas y reglas que no siempre tienen el mismo significado y no necesariamente están pensadas para alcanzar la igualdad real entre hombres y mujeres. Y ello responde al modelo universal interiorizado en las normas jurídicas del estado constitucional, el cual responde a unas características propias de los hombres, que no deja de ser una particularidad y una diferencia (Sevilla Merino, Ventura Franch y García Campá, 2007). De forma que, aunque se proclame una igualdad entre hombres y mujeres, la misma no llegará a producir los resultados deseados y esperados, porque el punto de origen es erróneo, ya que se construye sobre el prisma del hombre y, de esta forma, menciona Esquembre Cerdá (2016), como consecuencia de nombrar en masculino universal se borra del imaginario colectivo a las mujeres, al hacer al varón el término indispensable de comparación.

Parte de la doctrina afirma que ello es fácilmente observable si analizamos el lenguaje utilizado a lo largo del texto constitucional, el cual es claramente partidista de una sociedad masculina. De esto modo, sólo encontramos referencias claras a la mujer, como sujeto, en aspectos relacionados directamente con el ámbito doméstico (maternidad, matrimonio o sucesión a la corona en ausencia de varones o tras los mismos). Por el contrario, en el ámbito jurídico-político, social, económico o cultural sólo encontramos al hombre como sujeto predominante, incluso allí donde pudiera haberse empleado un término neutro, es el 
género masculino el elegido para representar al conjunto de la sociedad.

Sin embargo, atendiendo al Informe de la Real Academia Española sobre el lenguaje inclusivo y cuestiones conexas (2020), podríamos entender, en la mayoría de las ocasiones, que la norma emplea términos inclusivos, entendidos éstos como "aquellos términos que usados en masculino incluyen claramente en su referencia a hombres y mujeres, cuando el contexto deja suficientemente claro que ello es así, como ocurre con «Todos los españoles son iguales ante la ley»". Ahora bien, hay términos o contextos en los que el carácter inclusivo no se distingue claramente, pudiendo dar como resultado la homogeneización masculina del término.

Ante esta "tierra de nadie" ha sido la jurisprudencia quien ha ido concretando la percepción femenina de las regulaciones constitucionales, siendo clave la Sentencia del Tribunal Constitucional (STC) 103/1983, de 22 de noviembre, en materia de discriminación directa por razón de sexo. Posteriormente, profusa ha sido la jurisprudencia en este ámbito (como por ejemplo, con las SSTC 145/1991, de 22 de julio, que aboga por la igualdad salarial, la 214/2006, de 3 de julio, que otorgó amparo a la no discriminación de la mujer a causa de la maternidad, la 12/2008, de 29 de enero, donde se procede a reconocer la constitucionalidad de las cuotas electorales o la 59/2008, de 14 de mayo, donde se concreta la doctrina constitucional sobre la igualdad, entre otras), al igual que el desarrollo legislativo, a través del paquete normativo del reconocimiento de la igualdad efectiva entre hombres y mujeres. Pero tanto la jurisprudencia constitucional como las especificidades legales no dejan de actuar en un nivel infraconstitucional, cuyos éxitos no se reconocen en el texto constitucional, limitando las opciones de la mujer en desventaja con el hombre.

En consecuencia, como exige Zoco Zabala (2017), es necesario transformar las medidas de acción positiva para las mujeres en derechos. La crisis actual ha abierto el debate sobre la reforma constitucional, aprovechemos la misma para incluir la perspectiva de género adecuadamente y no sólo mediante tímidos retoques del articulado o interpretaciones colaterales ambiguas de los términos empleados en el texto constitucional, ya que, en palabras de Gómez Fernández (2019), la opción de no jugar para no perder, la opción de no abordar la deliberación, es la negación misma de la esencia del sistema democrático.

\section{A MODO DE CONCLUSIÓN}

La igualdad, como ha señalado Amorós (2005), es un concepto regulativo político, un concepto ético y un valor y, sobre todo en el ámbito del Derecho, y muy especialmente del Derecho constitucional, la igualdad representa uno de los principios más interesantes, pero quizás también más abstractos y más difíciles de concretar. Aunque ello no debe ser obstáculo para seguir luchando por encontrar una efectiva igualdad para los diversos miembros de una sociedad avanzada y democrática en derechos como la nuestra.

La historia, la traición, la cultura forman parte de nuestro desarrollo personal, de forma inevitable y consustancial, pero no debe ser el enclave interpretativo de todo cuanto nos rodea, sino justamente la herramienta de reflexión y análisis de nuestro presente y futuro. En un mundo tecnológicamente globalizado como el nuestro, donde las relaciones han dejado de ser únicamente personales y los canales de aprendizaje son infinitos y multimodales, nos encontramos sometidos a constantes procesos de socialización a través de atractivos tan potentes como los que ofrece el sector audiovisual, quien a través de su parcial y fraccionada visión del mundo perfila y moldea los parámetros selectivos de la sociedad. Una sociedad que tradicionalmente se ha desarrollado bajo un prisma únicamente masculino, ya que la 
mujer quedaba relejada a un ámbito íntimo, personal y doméstico, sin rostro ni voz en la construcción del nuevo mundo, pues así también era concebido por los medios de comunicación a través de las películas y largometrajes infantiles, visionadas una y otra vez en todos los hogares. Disney es la herramienta de entretenimiento, socialización y aprendizaje más grande del mundo, no en vano parte de la ilusión de su creador "si puedes soñarlo, puedes hacerlo", transformada en capacidad de persuasión sobre su audiencia.

De esta forma, la sociedad ha crecido sobre unos principios y valores partidistas y hegemónicamente masculinos que han socavado la posición de la mujer durante décadas. La normativa más reciente aboga por acabar con ese techo de cristal autoimpuesto, pero no es sino una falacia política más, ya que las mismas normas son creadas por un poder constituyente que no habla en femenino. La pretendida igualdad entre sexos es compleja en su origen y diversa en su aplicación, pues la sociedad se ha tornado exigentemente polifacética y donde antes era suficiente una profusa promulgación legislativa ahora se requiere un cambio en la estructura normativa fundamental. No basta con maquillar la constitución con pequeñas actualizaciones o reinterpretaciones lingüísticas ambiguas, sino que se requiere una modificación global del texto constitucional, al abrigo de la corresponsabilidad político-social en clave de género. Una sociedad moderna, evolucionada, activa, transformadora y en crecimiento no puede sino involucrar a la sociedad misma en su propio desarrollo. Un conjunto social formado por mujeres y por hombres, con iguales capacidades, habilidades, responsabilidades y oportunidades, sin clasificaciones patriarcales que dividan a la sociedad simplemente por ser mujer u hombre, creando roles y estereotipos obsoletos. Es necesario implementar nuevos canales de comunicación y educación sociocultural, como herramienta con la que combatir la tradición clasista heredada. Es decir, se requiere un esfuerzo común y conjunto para que hablar de género no implique connotaciones negativas para la mujer y que ésta pueda ser también reconocida en su verdadera dimensión política, como nos recuerda Torres Díaz (2014), al hablar de violencia de género.

Aunque tampoco hay que olvidar, que nuestra Constitución es fruto de un contexto histórico y político, donde se construyó la misma desde sus debilidades y fortalezas, con sus correlaciones de poder, sus ventajas, inconvenientes, miserias y alabanzas (Álvarez Rodríguez, 2020). No llevemos, pues, el feminismo al extremo de caer en el mismo error que los padres de la Constitución.

\section{BIBLIOGRAFÍA}

Aba Catoria, A. (2014). El gran olvido del constitucionalismo gaditano. En Castells, I. (Ed.). Mujeres y Constitucionalismo histórico español. Madrid: Centro de Estudios Políticos y Constitucionales, pp. 281-316.

Aguado Peláez, D. y Martínez García, P. (2015). ¿Se ha vuelto Disney feminista? Un nuevo modelo de princesas empoderadas, Área Abierta, 15(2), 49-61. Recuperado de: https://doi.org/10.5209/rev ARAB.2015.v15.n2.46544

Álvarez Rodríguez, A. (2020). ¿Es patriarcal la Constitución?, E-Legal History Review, 30, 1-16.

Amorós, Celia (2005): La gran diferencia y sus pequeñas consecuencias para la lucha de las mujeres. Madrid: Ediciones Cátedra.

Belmonte, J. y Guillamón, S. (2008). Co-educar la mirada contra los estereotipos de género en TV, Comunicar, XVI (31), 115-120. Recuperado de www.revistacomunicar.com

Carmona, E. (2007). Diez mega grupos controlan la prensa, radio y televisión de EEUU e influyen en América Latina, CubaDebate contra el Terrorismo Mediático. Disponible en https://goo.gl/rTvDtk 
Castro, O. (2008). Género y traducción: elementos discursivos para una reescritura feminista, Lectora, 14, 285-301. Recuperado de www.revistes.ub.edu

Digón, P. (2006). El caduco mundo de Disney: propuesta de análisis crítico en la escuela, Comunicar, 26, 163-169. Recuperado de www.revistacomunicar.com

Dorfman, A. y Mattelard, A. (1972). Para leer al Pato Donald. Comunicación de masas y colonialismo, México: Siglo XXI.

Esquembre Cerdá, M. (2016). Las mujeres ante el cabio constitucional. Algunos apuntes desde una perspectiva feminista para una 'reforma constituyente' de la Constitución Española, Revista Internacional de Estudios Feministas, 1(1), 184-212. Recuperado de https://doi.org/10.17979/arief.2016.1.1.1835

Giroux, H. (2001). El ratoncito feliz. Disney o el fin de la inocencia, Madrid: Fundación Germán Sánchez Ruipérez.

Gómez Fernández, I. (2017). Una constituyente feminista: ¿cómo reformar la Constitución con perspectiva de género?, Madrid: Marcial Pons.

Gómez Fernández, I. (2019). ¿Qué es eso de reformar la Constitución con perspectiva de género? Mitos caídos y mitos emergentes a partir del libro Una Constituyente feminista, Eunomía. Revista en Cultura de la Legalidad, 16, 312-329. Recuperado de https://doi.org/10.20318/eunomia.2019.4708

González, M.E., Villasuso, M. y Rivera, T. (2012). Las princesas de Disney: lo que aprenden las niñas mexicanas a través de las películas, Comunicación, 10(1), 1505-1520. Recuperado de: www.revistacomunicacion.org

Graciela Cayuso, S. (2009). El principio de igualdad. Problemas e interrogantes. El sistema constitucional argentino, Revista de Derecho Político, 75-76, 359-383. Recuperado de www.revistas.uned.es

Hyde, J.S. (2005). The gender similarities hypothesis, American Psychologist, 60, 581-592. Recuperado de https://doi.org/10.1037/0003-066X.60.6.581

Instituto Andaluz de la Mujer (2015). Yo miro desde la igualdad ¿Y tú?, Andalucía: Conserjería de Igualdad, Salud y Políticas Sociales.

López, M. y De Miguel, M. (2013). La fémina Disney: análisis y evolución del personaje femenino en cuatro películas de la factoría Disney, Sociedad y Economía, 24, 121-142. Recuperado de www.scielo.or.co

Loscertales Abril, T. y Núñez Domínguez, T. (2009). La imagen de la mujer en la era de la comunicación, Revista Científica de Información y Comunicación, 6, 427-462. Recuperado de www.institucional.us.es

Marín Díaz, V. y Solís, C. (2017). Los valores trasmitidos por las mujeres de las películas Disney, Revista CS, 23, 37-55. Recuperado de https://doi.org/10.18046/recs.i23.2296

Martín Sánchez, M. (2014). La mujer en los orígenes del constitucionalismo español: de su invisibilidad de derecho a la realidad de hecho, Estudios de Derecho, 71(158), 293-311.

Martínez Sempere, E. (2005). Hacia la plena ciudadanía. En Freixes San-juan, T. \& Sevilla Merino, J. (Coords.). Género, Constitución y Estatutos de Autonomía, Madrid: Instituto Nacional de Administración Pública, pp. 45-66.

Martínez Sempere, E. (2014). Ciudadanía democrática, voluntad política y estado social. En Igualdad y democracia: el género como categoría de análisis jurídico. Estudios en homenaje a la profesora Julia Sevilla Merino (pp. 443-451). Valencia: Corts Valencianes.

Martínez, A. y Merlino, A. (2006). Discurso y socialización en producciones infantiles, Comunicar, 26, 125-130. Recuperado de https://doi.org/10.3916/C26-2006-19

Matarón, C. (2015). El cine como herramienta pedagógica: una aproximación práctica para la enseñanza de la economía, Aula de Encuentro, 16(2), 42-54. Recuperado de www.revistaselectronicas.ujaen.es

Osuna-Acedo, S., Gil-Quintana, J. y Cantillo Valero, C. (2018). La construcción de la identidad infantil en el Mundo Disney, Revista Latina de Comunicación Social, 73, 1284-1307. Recuperado de https://doi.org/10.4185/RLCS-2018-1307

Pereira, C. (2006). Un ejemplo del cine como instrumento de educación en valores. El catobeplas. 
Revista Crítica del Presente, 48(23). Recuperado de: www.nodulo.org

Porto Pedrosa, L. (2010). Socialización de la infancia en películas de Disney/Pixar y Dramworks/Pdi, PrismaSocial, 4, 1-20. Recuperado de www.revistaprismasocial.es

Puelo, A. (2000). Filosofía, Género y pensamiento crítico, Valladolid: Universidad de Valladolid.

Renau i Manén, M.D. (2005). De súbditas a ciudadanas, Meridiam, 36, 12-13. Recuperado de www.dialnet.unirioja.es

Sevilla Merino, J, Ventura Franch, A. y García Campá, S. (2007). La igualdad efectiva entre hombres y mujeres desde la teoría constitucional, Revista del Ministerio de Trabajo y Asuntos Sociales, 67, 63-82. Recuperado de www.mitramiss.gob.es

Sevilla Merino, J. (2006). Las mujeres parlamentarias en la legislatura constituyente. Madrid: Cortes Generales.

Soler Sánchez, M. (2012). La igualdad de las mujeres y hombres en el Estado Autonómico: una visión sobre la introducción de la perspectiva de género en los Estatutos de Autonomía. En La Solidaridad en el Estado Autonómico, Valencia: Fundación Profesor Manuel Broseta, pp. 99-118.

Stolke, V. (2004). La mujer es puro cuento: la cultura del género, Revista Estudios Feministas, 12(2), 77-105.Recuperado de https://doi.org/10.1590/S0104-026X2004000200005

Stuven, A.M. (2013). La mujer ayer y hoy: un recorrido de incorporación social y política, Centro de Políticas Públicas, 8(91). 1-20. Recuperado de www.politicaspublicas.uc.cl

Thompson, T. y Zerbinos, E. (1995). Gender roles in animated cartoons. Has the pictures changed in 20 years? Sex Roles, 21, 651-673. Recuperado de https://doi.org/10.1007/BF01544217

Torres Díaz, M.C. (2014). El derecho a una vida libre de violencia de género como derecho fundamental: crítica constitucional desde el paradigma feminista. En Igualdad y democracia: el género como categoría de análisis jurídico. Estudios en homenaje a la profesora Julia Sevilla Merino. Valencia: Corts Valencianes, pp. 643-656.

Torres Díaz, M.C. (2019). Las mujeres como sujeto constituyente: la crisis de los 40 ante la reforma constitucional, Revista Valenciana d'Estudis Autonòmics, 64, 160-185.

Torrez Díaz, M.C. (2018). Reseña de Gómez Fernández, I. (2017): Una constituyente feminista: ¿cómo reformar la Constitución con perspectiva de género?, Madrid: Marcial Pons, en Feminismo/s, 31, 269-275. Recuperado de: https://doi.org/10.14198/fem.2018.31.15

Zaragoza Martí, M.F. (2017). El agua como elemento de reflexión ético-política en el nuevo paradigma de la gobernabilidad migratoria, Barataria, 23, 175-184. Recuperado de: https://doi.org/10.20932/barataria.v0i23.341

Zoco Zabala, C. (2017). Igualdad entre mujeres y hombres tras 40 años de Constitución Española, Revista de Derecho Público, 100, 211-256. Recuperado de https://doi.org/10.5944/rdp.100.2017.20687

\section{Breve currículo:}

\section{María Francisca Zaragoza-Martí}

Profesora de derecho constitucional de la Facultad de Derecho de la Universidad de Alicante (España). Doctora en Derecho con Mención Internacional por la Universidad Miguel Hernández de Elche (España). Investigadora en el área de derechos humanos, concretamente en la catalogación, clasificación y reivindicación de nuevos derechos. Ponente en diversos congresos nacionales e internacionales y autora de diversos artículos científicos y capítulos de libro relacionados con la línea de investigación. Miembro del Instituto de Geografía y del Instituto del Agua y de las Ciencias Ambientales, de la Universidad de Alicante, con líneas de investigación sobre el derecho al agua, al paisaje fluvial o el derecho a la ciudad, entre otros. 